\title{
Hypoxic and hypercapnic response in asthmatic subjects with previous respiratory failure
}

\author{
ARLENE A HUTCHISON, ANTHONY OLINSKY \\ From the Department of Thoracic Medicine, Royal Children's Hospital, Melbourne, Australia
}

ABSTRACT Three children and two young adults with severe asthma who had frequent episodes of respiratory failure were studied. Isocapnic hypoxia and hyperoxic hypercapnia were produced separately using a rebreathing apparatus. Alveolar carbon dioxide tension and oxygen tension were estimated by continuously sampling expired gases. The three young children had a diminished response to hypoxia but a normal response to hypercapnia when compared to control asthmatic children $(\mathrm{p}<0.05)$ or healthy children $(\mathrm{p}<0.05)$. The two young adult patients had a normal response to hypoxia but one had a low response to hypercapnia. Studies of parents of these patients suggested that familial factors in part may determine the degree of response to hypoxia. It is suggested that the chance combination of a possibly familial, inappropriate response to hypoxia with severe asthma would lead to a risk of respiratory failure.

The degree of ventilatory response to hypoxia and hypercapnia is controlled, in part, by familial factors. Long distance runners and their non-athletic family members have an abnormally low response to hypoxia. ${ }^{1}$ Similarly, healthy offspring of hypercapnic patients with chronic obstructive airways disease have a decreased response to carbon dioxide when compared to offspring of normocapnic patients. ${ }^{2}$ In contrast, environmental factors such as long-term residence at high altitude may lead to an acquired blunted response to hypoxia. ${ }^{3}$ Diseases causing prolonged hypoxia such as cyanotic congenital heart disease $^{4}$ or chronic lung disease ${ }^{5}$ may also lead to a diminished response to hypoxia.

Asthmatics as a group have a normal response to hypoxia and hypercapnia. ${ }^{6}$ In fact, in certain situations, such as adding an external resistive or elastic load, the response as measured by Pm 100 is increased. ${ }^{67}$ However, an individual patient with a combination of severe asthma and an unrelated, inappropriately low, familial response to hypoxia or hypercapnia could be at a disadvantage during a period of increased airways obstruction and may be at risk of respiratory failure or sudden death. Hudgel and $\mathrm{Weil}^{8}$ have described a 17 -year-old asthmatic who was unusually hypoxaemic and who, with three of four members of the family, had a decreased response to hypoxia.

The purpose of this study was to examine the

No reprints of this paper will be available. ventilatory response to hypoxia and hypercapnia in a group of five children and young adults with asthma who had previous episodes of respiratory failure, respiratory arrest, or loss of consciousness. If abnormal ventilatory control was found, it was hoped that study of their parents might reveal any familial factors.

\section{Methods}

Subjects were selected on the basis of (1) recurrent episodes of respiratory failure, loss of consciousness, or respiratory arrest attributed to asthma, and (2) sufficient comprehension and neuromotor development to perform repeated pulmonary function tests.

Three older children (aged 10 to 12 years) and two young adults (aged 18 years) who conformed to these criteria were studied. Two had multiple episodes of acute bronchoconstriction and associated loss of consciousness occurring at night usually at home. The others had more than one episode of respiratory failure and one had required a period of mechanical ventilation. Parents of patients with a low response to either carbon dioxide or oxygen were tested. One father was not available for testing and one mother was unable to establish a baseline alveolar carbon dioxide above $30 \mathrm{mmHg}$ because anxiety-provoked hyperventilation made her hypoxic response curve invalid.

Because the normal value for ventilatory response 
to hypoxia is lower in children aged 10 to 12 years ${ }^{9}$ but is independent of age in early to middle age adult life, ${ }^{10}$ two control groups were used. Seven healthy older children aged 9 to 13 years and 14 healthy adults aged 20 to 40 (three smokers and 11 nonsmokers) were studied. All healthy controls had normal spirometry, had never lived at high altitude, and had never undertaken athletic training. Six adolescents with a similar degree of asthma to the patients but with no episodes of respiratory failure were also studied.

The hypercapnic response was measured using the method of Read. ${ }^{11}$ The subject breathed room air through a two-way valve (Hans Rudolph pediatric valve) until stable ventilation was reached and then, from the end of expiration the subject rebreathed from a bag filled with a mixture of $50 \%$ oxygen, $4 \%$ carbon dioxide, and $46 \%$ nitrogen. The volume used was the subject's vital capacity plus 1 litre if a child and 1.5 litres if an adult. Tidal volume was measured using a Krogh spirometer attached to a bag in a box. Expired gas was sampled continuously for $\mathrm{CO}_{2}$ (Beckman LB2) and $\mathrm{O}_{2}$ (Beckman OM11) and returned to the system to prevent a shifting baseline. Tidal volume, and percentages of $\mathrm{CO}_{2}$ and $\mathrm{O}_{2}$ were recorded continuously on an eight-channel recorder (Hewlett Packard 748B). The end-tidal $\mathrm{CO}_{2}$ level slowly rose by 15 to $20 \mathrm{mmHg}$ over three to five minutes and end-tidal $\mathrm{O}_{2}$ remained above the subject's baseline level when breathing room air.

Minute ventilation ( $\dot{V} E)$ was calculated using three to four breaths with a constant end-tidal $\mathrm{CO}_{2}$ and was expressed as $1 /$ minute at ATPS. Minute ventilation was calculated for every $2-3 \mathrm{mmHg}$ change in $\mathrm{CO}_{2}$ tension and plotted against alveolar $\mathrm{CO}_{2}$ $\left(\mathrm{PaCO}_{2}\right)$. (It was assumed that end-tidal $\mathrm{CO}_{2}$ was approximately equal to $\mathrm{PaCO}_{2}$.) The graph of $\dot{\mathrm{V} E}$ vs $\mathrm{PaCO}_{2}$ yielded a staight line with slope $\mathrm{S}$ (using least squares method). $S$ is the slope of the line expressed as change in ventilation per unit change in $\mathbf{P a C O}_{2}$, litres $/ \mathrm{min} / \mathrm{mmHg}$. The higher $\mathrm{S}$, the greater the response to $\mathrm{CO}_{2}$.

The hypoxic response was measured according to the method of Rebuck and Campbell12 using the $\stackrel{\mathbb{D}}{\Omega}$ same circuit. The subject breathed room air through क the valve until a stable end-tidal $\mathrm{PaCO}_{2}$ in the normal $\vec{\circ}$ range of $35-45 \mathrm{mmHg}$ was achieved. At the end of expiration, he or she was switched into the re- $\vec{\omega}$ breathing bag which contained $23 \% \mathrm{O}_{2}, 4 \% \mathrm{CO}_{2}$, and $73 \% \mathrm{~N}_{2}$. The volume of gas mixture again $\overrightarrow{\vec{x}}$ varied according to the subject's vital capacity. As the subject rebreathed, $\mathrm{O}_{2}$ was consumed and the end-tidal $\mathrm{O}_{2}$ dropped progressively from over 100 $\mathrm{mmHg}$ to $37-40 \mathrm{mmHg}$ over five to eight minutes. of The end-tidal $\mathrm{CO}_{2}$ tension was maintained at a 0 constant level using a scrubber system consisting of cannisters of soda lime and a Sarns variable cardiac bypass pump.

Tidal volume, expired $\% \mathrm{CO}_{2}$ and $\% \mathrm{O}_{2}$ were continuously recorded on the eight-channel recorder. For the $\mathrm{O}_{2}$ response curve $\dot{\mathrm{V}} \mathrm{E}$ was calculated for $\vec{\bullet}$ every $3-4 \mathrm{mmHg}$ change in $\mathrm{O}_{2}$ tension and a graph $\stackrel{\infty}{-}$ of $\dot{\mathrm{V}}$ against $\mathrm{PaO}_{2}$ yielded the classical curve with the formula $\dot{\mathrm{V}} \mathrm{E}=\frac{\mathrm{Vo}+\mathrm{A}}{\left(\mathrm{PaO}_{2}-32\right)}$ where $\mathrm{Vo}$ is the asymptote for ventilation and $\mathrm{A}$ the degree of curvature. A was calculated as described by ByrneQuinn et al. ${ }^{9}$ The larger A, the greater the response to hypoxia.

Subjects performed $\mathrm{CO}_{2}$ and $\mathrm{O}_{2}$ response tests in random order with a 10 to 15 minute rest period in between. All subjects with an abnormal hypoxic response had a duplicate test. No caffeinated beverages or theophylline containing medicines were allowed for at least six hours before testing. Spirometry was performed using a nine litre water-filled spirometer. Informed consent was obtained from all subjects and also the parents of subjects who were under 18 years of age.

Table 1 Control hypoxic and hypercapnic data

\begin{tabular}{|c|c|c|c|c|}
\hline \multirow[t]{2}{*}{ Group } & \multicolumn{4}{|c|}{ Hypoxic data } \\
\hline & Number & Age $(y r)$ & $F E V_{1 \cdot 0} / V C$ & $S(A T P S)$ \\
\hline $\begin{array}{l}\text { Healthy adults } \\
\text { Healthy children } \\
\text { Control asthmatics }\end{array}$ & $\begin{array}{r}14 \\
5 \\
6\end{array}$ & $\begin{array}{l}30 \pm 1.9 * \\
12 \pm 0.4 \\
14 \pm 0.8\end{array}$ & $\begin{array}{l}80 \pm 2 \cdot 3 \\
80 \pm 2 \cdot 6 \\
58 \pm 4 \cdot 1\end{array}$ & $\begin{array}{r}105 \pm 16 \cdot 3 \\
66 \pm 14 \cdot 2 \\
95 \pm 26 \cdot 0\end{array}$ \\
\hline \multirow[t]{2}{*}{ Group } & \multicolumn{4}{|c|}{ Hypercapnic data } \\
\hline & Number & $A g e(y r)$ & $F E V_{1 \cdot 0} / V C$ & $S(A T P S)$ \\
\hline $\begin{array}{l}\text { Healthy adults } \\
\text { Healthy children } \\
\text { Control asthmatics }\end{array}$ & $\begin{array}{l}7 \\
4 \\
5\end{array}$ & $\begin{array}{l}33 \pm 3.7 \\
13 \pm 1.6 \\
14 \pm 0.9\end{array}$ & $\begin{array}{l}81 \pm 3 \cdot 3 \\
90 \pm 3 \cdot 9 \\
57 \pm 4 \cdot 6\end{array}$ & $\begin{array}{l}1.91 \pm 0.38 \\
1.58 \pm 0.50 \\
1.11 \pm 0.11\end{array}$ \\
\hline
\end{tabular}

ATPS = ambient temperature, pressure, saturation.

*Mean \pm standard error of the mean. 
Table 2 Patients' and parents' hypoxic and hypercapnic data

\begin{tabular}{|c|c|c|c|c|c|c|}
\hline & $\operatorname{Age}(y r)$ & Sex & $F E V_{1.0} ! V C$ & $A(A T P S)$ & $\mathrm{PCO}_{2}{ }^{*}$ & $S(A T P S)$ \\
\hline \multicolumn{7}{|c|}{ Children and parents } \\
\hline Patient 1 & 12 & $\mathbf{F}$ & 43 & $\mathbf{0}$ & 36 & 0.87 \\
\hline Father & 33 & $\mathbf{M}$ & 79 & 22 & 38 & $2 \cdot 18$ \\
\hline Mother & 30 & $\mathbf{F}$ & 74 & 145 & 41 & $1 \cdot 43$ \\
\hline Patient 2 & 12 & $\mathbf{M}$ & 55 & 35 & 36 & 0.62 \\
\hline Mother & 36 & $\mathbf{F}$ & 72 & 111 & 44 & 1.05 \\
\hline Patient 3 & 10 & $\mathbf{M}$ & 63 & 25 & 33 & 0.98 \\
\hline Father & 37 & $\mathbf{M}$ & 70 & 244 & 42 & 2.03 \\
\hline Mother & 33 & $\mathbf{F}$ & 85 & 58 & 40 & 1.33 \\
\hline \multicolumn{7}{|c|}{ Young adults and parents } \\
\hline Patient 4 & 18 & $\mathbf{M}$ & 45 & 81 & 36 & 0.55 \\
\hline Father & 54 & $\mathbf{M}$ & 67 & 173 & 38 & $1 \cdot 36$ \\
\hline Mother & 50 & $\mathbf{F}$ & 71 & - & - & $1 \cdot 23$ \\
\hline Patient 5 & 18 & $\mathbf{M}$ & 31 & 197 & 38 & $1 \cdot 18$ \\
\hline
\end{tabular}

*Subjects baseline $\mathrm{PCO}_{2}$ at which hypoxic response tested.

Comparisons of $\mathbf{A}$ and $\mathbf{S}$ between groups were made using Student's unpaired $t$ test.

\section{Results}

\section{CONTROLS}

Mean values for parameters $A$ and $S$ are shown in table 1. As a group, A tended to be lower in the normal children. The value of $A$ for control adolescent asthmatics was not significantly different from healthy subjects. The hypercapnic response, $\mathrm{S}$,

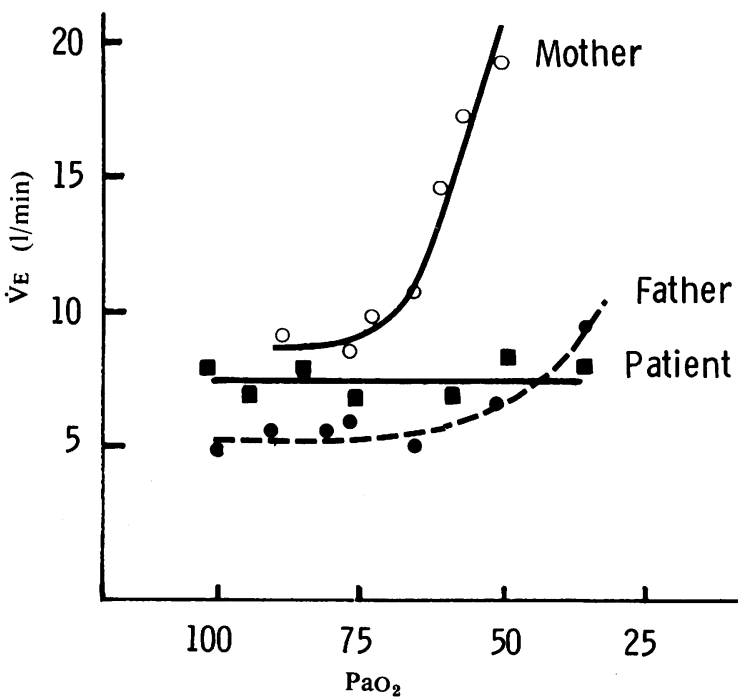

Figure Graph of minute ventilation $(\dot{V} \mathrm{E})$ vs $\mathrm{PaO}_{2}$ in patient 1 and her parents. The patient had no significant increase in $\dot{V}$ with increasing hypoxia to a level of 37 $\mathrm{mmHg}$. The father's response appeared to be inappropriately low $(A=22)$ and the mother's response was appropriate $(A=145)$. tended to be lower in the adolescent asthmatic controls but this did not reach statistical significance. There was no significant difference in the degree of airways obstruction between the patients and control adolescent asthmatics as assessed by spirometry.

\section{PATIENTS}

The 10 and 12-year-old patients had a significantly lower response to hypoxia than normal controls of the same age $(p=0.02)$ or asthmatics $(p=0.04)$ but the response to $\mathrm{CO}_{2}$ was not significantly different (table 2).

The two 18-year-old patients had a normal response to hypoxia. Patient 5 also had a normal hypercapnic response while patient 4 had the lowest response to $\mathrm{CO}_{2}$ of the entire group (controls plus patients). However, because of the wide SD of the measurement, this value was still within 2 SD of the mean (2 SD from the mean for $\mathrm{S}$ is -0.09 ).

\section{PARENTS}

Patients 1 and 3 both had one parent with a value for $A$ well below the mean (figure). In the third patient with a low A, only one parent was available and her response was normal. The parents all had a normal hypercapnic response.

\section{Discussion}

Respiratory failure in chronic asthma may not be simply an intolerable increase in airways obstruction but rather failure of the integrated system to assess and adjust to the increasing load. Inappropriate neurochemical response and respiratory muscle fatigue are two examples of possible mechanisms involved in the failure of the total system. In this study, asthmatic patients were selected on the basis 
of recurrent episodes of respiratory failure or loss of consciousness - that is, a presumptive clinical diagnosis of inappropriate ventilatory control had been made. Of the five, three had an abnormal response to hypoxia and one possibly had a low response to carbon dioxide.

One possible explanation for this decreased ventilatory response is that the patients had severe airways obstruction and were unable to increase their ventilation. This does not appear to be the case. Firstly, each patient with a low response to $\mathrm{O}_{2}$ showed a normal increase in ventilation with rising $\mathrm{CO}_{2}$. (The one subject with a low response to $\mathrm{CO}_{2}$ responded well to $\mathrm{O}_{2}$.) Secondly, a group of control adolescents with severe airways obstruction but no episodes of respiratory failure demonstrated normal neurochemical control. Finally, other investigations have shown an increased respiratory drive in asthmatics during methacholine-induced bronchoconstriction. ${ }^{7}$ Another possible explanation is that the decreased response was acquired because of long-term hypoxia, a situation analogous to high altitude residence. Again this seems unlikely because of the age of the patients: the blunted response in high altitude dwellers is only partial after 10 years of residence and not complete until 20 years. ${ }^{9}$ A more likely explanation is that the decreased hypoxic or hypercapnic response and chronic asthma occurred independently. In an interesting study of 19 asthmatics during recovery from severe asthma Rebuck and Read ${ }^{13}$ showed that while the majority of their patients increased their hypercapnic response with improvement in their $\mathrm{FEV}_{1}$, three did not. These three patients showed elevation of arterial $\mathrm{CO}_{2}$ tension at the time of presentation. Although the studies in the parents of our subjects are not conclusive there is a suggestion of a familial factor in the two families. The number of parents in this study is too small to assess the contribution of environmental and genetic factors. However, Collins et al ${ }^{14}$ studied 24 pairs of identical and non-identical twins and concluded that hereditary factors influenced the response to hypoxia but not hypercapnia.

If the hypothesis is correct, then the abnormal hypoxic response is familial and antedates the appearance of asthmatic symptoms. However, none of the patients experienced respiratory failure before the age of 8 years. Therefore the presence of an inappropriately low response to hypoxia in an asthmatic does not explain fully the occurrence of respiratory failure. Rather, an associated change in the severity of the airways obstruction may be involved as these episodes are seen in severe chronic asthmatics and their frequency varies as does the disease. In asthmatics, the neurochemical drive and resistive load detection may act synergistically-that is, the presence of both stimuli results in a greater response than seen in normal subjects exposed to the same stimuli. ${ }^{7}$ If resistive load detection is also subnormal in these patients with a low response to $\mathrm{O}_{2}$, an exacerbation of their airways obstruction could lead to a risk of respiratory failure or sudden death. Why patients with a low hypoxic response and a normal hypercapnic response, which is possibly a more sensitive drive, do not maintain ventilation is not understood.

The present data plus the previous studies on familial effects lead to several speculations. Rather than thinking of neurochemical control as showing a wide range of responses perhaps it would be more helpful to think in terms of appropriate and inappropriate responders. If an inappropriate response were inherited several high risk situations could be envisaged. The chance combination of severe asthma and an inappropriate response would result in a risk of respiratory arrest or sudden death.

We acknowledge gratefully the critical analysis and helpful advice of Dr LI Landau and Dr PD Phelan, the technical assistance of L McLennan, and the secretarial assistance of $\mathrm{J}$ Matheson. The paper was presented in part at the Paediatric Research Society of Australia, Sydney, Australia in May 1980.

\section{References}

${ }^{1}$ Scoggin CH, Doekel RD, Kryger MH, Zwillich CW, Weil JV. Familial aspects of decreased hypoxic drive in endurance athletes. J Appl Physiol 1978;44:464-8.

2 Mountain R, Zwillich C, Weil J. Hypoventilation in obstructive lung disease: the role of familial factors. $N$ i Engl J Med 1978;298:521-5.

${ }^{3}$ Lenfant C, Sullivan K. Adaptation to high altitude. $N$ Engl J Med 1971;284:1298-309.

${ }^{4}$ Sorensen CS, Severinghaus JW. Respiratory insensitivity to acute hypoxia persisting after correction of tetralogy $\mathrm{O}$ of Fallot. J Appl Physiol 1968;25:221-3.

${ }^{5}$ Bradley CA, Fleetham JA, Anthonisen NR. Ventilatory $\frac{D}{2}$ control in patients with hypoxemia due to obstructive lung disease. Am Rev Respir Dis 1979;120:21-30.

- Cosgrove JF, Neuburger N, Levison H. The ventilatory $\Omega$ response to carbon dioxide in asthmatic children, $N$ measured by the mouth-occlusion method $\left(P_{M_{100}}\right)$. N
Pediatrics 1976;57:952-9.

${ }^{7}$ Kelsen SG, Fleegler B, Altose MD. The respiratory neuro- $\sigma$ muscular response to hypoxia, hypercapnia, and obstruction to airflow in asthma. Am Rev Respir Dis 1979;120:517-27.

${ }^{8}$ Hudgel DW, Weil JV. Asthma associated with decreased $\stackrel{\mathcal{O}^{+}}{?}$ hypoxic ventilatory drive: a family study. Ann Intern Med 1974;80:622-5.

- Byrne-Quinn E, Sodal IE, Weil JV. Hypoxic and hypercapnic ventilatory drives in children native to high $\frac{\rho}{\Phi}$ altitude. J Appl Physiol 1972;32:44-6.

10 Hirshman CA, McCullough RE, Weil JV. Normal values $\sigma$ for hypoxic and hypercapnic ventilatory drives in man. J Appl Physiol 1975;38:1095-8. 
${ }^{11}$ Read DJC. A clinical method for assessing the ventilatory response to carbon dioxide. Aust Ann Med 1967;16: 20-32.

12 Rebuck AS, Campbell EJM. A clinical method for assessing the ventilatory response to hypoxia. Am Rev Respir Dis 1974;109:345-50.
13 Rebuck AS, Read J. Patterns of ventilatory response to carbon dioxide during recovery from severe asthma. Clin Sci 1971;41:13-21.

14 Collins DD, Scoggin CH, Zwillich CW, Weil JV. Hereditary aspects of decreased hypoxic response. $J$ Clin Invest 1978;62:105-10. 